\title{
The Association Between Arg72Pro C>G Polymorphism in the p53 Gene and the Risk of Obesity
}

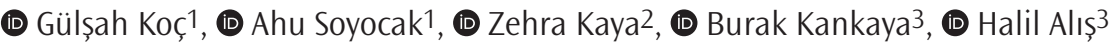 \\ 1 istanbul Aydın University Faculty of Medicine, Department of Medical Biology, i̇stanbul, Turkey \\ 2Van Yüzüncü Yıl University Faculty of Medicine, Department of Medical Biology, Van, Turkey \\ 3istanbul Aydın University VM Medical Park Florya Hospital, Clinic of General Surgery, İstanbul, Turkey
}

\section{ABSTRACT}

Introduction: The role of genetic factors in obesity has long been recognized, but their involved specific genes remained unidentified. The relationship between $p 53$ gene single nucleotide polymorphisms and the risk of obesity has been investigated in recent years. Therefore, this study aimed to investigate the association of p53 Arg72Pro C $>$ G (rs1042522) polymorphism with the risk of obesity in our study.

Methods: This study included 52 patients with obesity ( 26 were females and 26 were males) and 52 normal-weight healthy controls. Genomic DNA isolation was performed from the blood samples of all participants. P53 Arg72Pro C>G (rs1042522) polymorphism was detected by real-time quantitative polymerase chain reaction from genomic DNA samples.

Results: No significant associations were identified between Arg72Pro (rs1042522) P53 polymorphism and obesity risk. Glucose levels are significantly different between the obese and control groups with the CC and CG genotypes, but without difference in the GG homozygous genotype.

Conclusion: Our study is one of the first to investigate the relationship between p53 codon 72 polymorphisms and obesity risk but revealed no correlation between them. The relatively small number of participants may limit our study. Further research is needed in a large cohort to associate the $p 53$ gene Arg72Pro C $>$ G (rs1042522) variant with obesity risk.

Keywords: P53, risk of obesity, single nucleotide polymorphism

\section{Introduction}

Obesity is a disease that occurs when caloric intake and expenditure imbalance, resulting in increased visceral adiposity and systemic lowgrade chronic inflammation. Obesity is caused by several factors, including metabolic, social, environmental, and genetic (1). Obesity has become a global health problem that is linked to various diseases, including diabetes mellitus, hypertension, metabolic syndrome, atherosclerosis, and cancer. Aside from the exogenous and endogenous variables, the role of genetic factors in obesity has long been recognized, but the specific genes involved have not yet been thoroughly identified (2).

One of the genes that play a central role in intracellular metabolic pathways is p53. P53, commonly known as the tumor suppressor gene, is a transcription factor that controls gene expression in the cell cycle, DNA repair, differentiation, and apoptosis (3). Furthermore, it regulates various metabolic activities, including glycolysis, glycogen synthesis, oxidative phosphorylation, and lipogenesis (4). P53 directly suppresses the expression of two glucose transporters (GLUT), GLUT1 and GLUT4 in glucose metabolism, leading to reduced glucose flux (5). P53 inhibits lipid synthesis while promoting fatty acid oxidation by inducing the expression of carnitine acetyltransferase genes, which transport fatty acids to the mitochondria for oxidation (6). In adipogenesis, it promotes brown adipocyte development while suppressing white adipocyte differentiation (7).

Many polymorphisms have been discovered in the $p 53$ gene's promoter, exon, and intron regions. P53 single nucleotide polymorphisms (SNPS) have been linked to a higher risk of cancer, autoimmune disorders, diabetes, and obesity in numerous studies $(8,9)$. The most widely investigated p53 polymorphism is Arg72Pro C>G (rs1042522), which occurs at codon 72 and has been proven to alter p53 function (10). In 55,521 Europeans, the $\mathrm{G}$ allele located at p53 codon 72 was associated with an increased prevalence of type 2 diabetes (11). The Arg72 variant increases the ability of p53 to induce apoptosis, while the pro-encoding allele has a lower apoptotic activity (12). The increased apoptotic rate of pancreatic beta cells causes impaired insulin secretion, which sometimes results in elevated plasma glucose (11). A study that consist of 136 patients with obesity and 122 healthy subjects revealed the relationship between the p53 rs1042522 GG genotype and obesity risk with men with 
obesity, showing a three-fold higher risk with the GG genotype (13). No other study has yet been performed in the literature that revealed the association of $\mathrm{p} 53$ Arg72Pro C $>\mathrm{G}$ variant with obesity. With the proven effect of this SNP on obesity, its use as a biomarker may be possible. Therefore, this study aimed to investigate the association between p53 Arg72Pro C $>$ G polymorphism and obesity risk in our study.

\section{Methods}

\section{Study Subjects}

The study included 52 patients with obese (26 females and 26 males) and 52 normal-weight healthy individuals (28 females and 24 males) between the ages of 18 and 65 years who presented to the istanbul Aydin University VM Medical Park Florya Hospital, General Surgery Department with complaints of overweight and related symptoms. The study group was formed by calculating the body mass index (BMI) $[(\mathrm{kg})] /$ height $\left.^{2}\left(\mathrm{~m}^{2}\right)\right]$. The BMI, demographic data, and laboratory values were collected according to standard procedures (Table 1). The mean age was 36.00 (29.50-43.50) years for patients with obesity and 36.50 (32.00-43.00) years in the control group. Psychotic or bipolar disorders, eating disorders, pregnancy and lactation, and documented cancer are all exclusion factors. The study protocol complies with the 2013 Helsinki Declaration ethical guidelines and was approved by the İstanbul Aydın University Ethics Committee (approval number: B.30.2. AYD.0.00.00.050-06.04/589). The informed consent form was obtained from all participants.

\section{DNA Extraction and Genotyping}

Venous blood samples were taken from all individuals who voluntarily agreed to participate in the study. Genomic DNA isolation was performed using the spin column method following the protocol of the commercial kit (Jena, Bioscience). A nanodrop spectrophotometer was used to evaluate the purity of DNAs (Epoch, Biotek). DNA samples with an absorbance value -was detected by real-time quantitative polymerase chain reaction (qRT-PCR) from genomic DNA samples (7500 Fast RT-PCR System, Applied Biosystems). qRT-PCR was performed with a total volume of $10 \mu \mathrm{L}$ for each sample using $2.75 \mu \mathrm{L}$ of $\mathrm{dH} 20,5 \mu \mathrm{L}$ of master mix kit (TaqMan, Thermo Fisher Scientific Inc.), $0.25 \mu \mathrm{L}$ of genotyping assay kit (TaqMan, Applied Biosystems, Waltham, MA, ABD) (Assay ID: C_2403545_10), and $2 \mu \mathrm{L}$ DNA (10 ng/ $\mu \mathrm{L}$ ). The DNA sequence of the probe used to determine the changing base of the SNP is "AGGAGCTGCTGGTGCAGGGGCCCACG[C/G]GGGGAGCAGCCTCTGGCATTCTGG" (Thermo Fisher Scientific), and its luminescence in the device changes based on the allele-specific VIC/FAM fluorescent dye. qRT-PCR conditions were set as 40 cycles of $15 \mathrm{~min}$ at $95^{\circ} \mathrm{C}$ and $1 \mathrm{~min}$ at $60^{\circ} \mathrm{C}$ after an initial denaturation step of $10 \mathrm{~min}$ at $95^{\circ} \mathrm{C}$. Results were analyzed according to VIC/FAM illumination pattern.

\section{Statistical Analysis}

Study data analyses were performed using the Statistical Package for the Social Sciences version 19 (IBM Co., Ltd., Chicago, IL, USA). The Shapiro-Wilk and Levene tests were used to determine the normality and homogeneity of variances. The Mann-Whitney $U$ test was used to compare the differences between two independent groups when the variable is continuous, but not normally distributed. The chi-square test was performed to evaluate the distribution of genotype and allele frequencies of p53 polymorphisms. A p-value of $<0.05$ was used to determine statistical significance.

\section{Results}

This study included 52 patients with obesity and 52 normal-weight controls. The overall clinical characteristics of all participants are

Table 1. Comparison of variables in obese and control group, as well as by gender

\begin{tabular}{|c|c|c|c|c|}
\hline & Variables & $\begin{array}{l}\text { Control }(n=52) \\
\text { Median }(25-75 \%)\end{array}$ & $\begin{array}{l}\text { Obese }(n=52) \\
\text { Median }(25-75 \%)\end{array}$ & p \\
\hline \multirow{4}{*}{ Study group } & Age (year) & $36.50(32.00-43.00)$ & $36.00(29.50-43.50)$ & 0.376 \\
\hline & $\mathrm{BMI}\left(\mathrm{kg} / \mathrm{m}^{2}\right)$ & $22.64(20.25-24.00)$ & $42.25(39.25-45.70)$ & $0.001^{k * k *}$ \\
\hline & Glucose (mg/dL) & $78.00(75.00-83.50)$ & $103.50(87.00-122.00)$ & $0.001^{* * * *}$ \\
\hline & HOMA-IR index & $1.05(0.74-1.17)$ & $18.36(11.35-21.10)$ & $0.001^{* * *}$ \\
\hline Gender & Variables & $\begin{array}{l}\text { Control }(n=28) \\
\text { Median }(25-75 \%)\end{array}$ & $\begin{array}{l}\text { Obese }(n=26) \\
\text { Median }(25-75 \%)\end{array}$ & $\mathbf{p}$ \\
\hline \multirow{5}{*}{ Women } & Age (year) & $34.50(29.50-41.00)$ & $35.50(29.00-44.00)$ & 0.924 \\
\hline & $\mathrm{BMI}\left(\mathrm{kg} / \mathrm{m}^{2}\right)$ & $22.11(19.94-23.34)$ & $40.25(37.50-42.67)$ & $0.001^{* * * *}$ \\
\hline & Glucose (mg/dL) & $78.00(76.50-84.00)$ & $111.00(85.00-119.00)$ & $0.001^{* * * *}$ \\
\hline & HOMA-IR index & $1.05(0.86-1.33)$ & $18.36(11.20-20.00)$ & $0.001^{* * * *}$ \\
\hline & Variables & $\begin{array}{l}\text { Control }(n=24) \\
\text { Median }(25-75 \%)\end{array}$ & $\begin{array}{l}\text { Obese }(n=26) \\
\text { Median }(25-75 \%)\end{array}$ & $\mathbf{p}$ \\
\hline \multirow{4}{*}{ Men } & Age (year) & $42.00(35.00-48.50)$ & $36.00(32.00-43.00)$ & 0.173 \\
\hline & $\mathrm{BMI}\left(\mathrm{kg} / \mathrm{m}^{2}\right)$ & 23.68 (21.95-24.33) & $45.00(41.50-46.50)$ & $0.001^{* * * *}$ \\
\hline & Glucose (mg/dL) & $78.00(74.50-78.00)$ & $102.00(89.00-128.00)$ & $0.001^{* * * *}$ \\
\hline & HOMA-IR index & $1.05(0.65-1.05)$ & $18.36(13.30-21.50)$ & $0.001^{* k * k}$ \\
\hline
\end{tabular}

Mann-Whitney U; values are expressed as median (25-75\%). BMI: body mass index, HOMA-IR index: Homeostatic model assessment for insulin resistance, kg: kilogram, m: meter, mg: milligram, dL: deciliter, $p$-value ${ }^{*} p<0.05,{ }^{* *} p<0.01,{ }^{* * *} p<0.001$ 
presented in Table 1. The mean BMI of the obese participants was 42.25 (39.25-45.70), whereas 22.64 (20.25-24.00) in the normal-weight control group. Glucose $(p<0.001)$ and insulin resistance [Homeostatic Model Assessment for Insulin Resistance (HOMA-IR) Index] $(p<0.001)$ were significantly different between the two groups. Likewise, glucose $(p<0.001)$ and HOMA-IR Index $(p<0.001)$ were significantly different between the obese and healthy controls in males and females (Table 1).
The genotype frequencies of the P53 Arg72Pro (rs1042522) polymorphism and its associations with obesity are summarized in Table 2. The frequency of the C allele was $70(67.3 \%)$ in the control group and $63(60.6 \%)$ in the obese group, whereas the $\mathrm{G}$ allele was $34(32.7 \%)$ in the control group and 41 (39.4\%) in the obese group. No significant associations were identified between the Arg72Pro (rs1042522) P53 polymorphism and obesity risk. The distribution of Arg72Pro (rs1042522) and p53 rs1042522 variant by BMI of males and females are summarized

\section{Table 2. Distribution of p53 genotypes in obese and control group, as well as by gender}

\begin{tabular}{|c|c|c|c|c|c|c|}
\hline $\begin{array}{l}\text { SNP } \\
\text { (rs1042522) }\end{array}$ & Variant & Control $(n=52)(n, \%)$ & Obese $(n=52)(n, \%)$ & OR $(95 \% \mathrm{Cl})$ & $\chi^{2}$ & $\mathbf{p}$ \\
\hline & CC (Pro/Pro) & $22(42.3)$ & $19(36.5)$ & 1 & - & Ref \\
\hline & CG (Pro/Arg) & $26(50.0)$ & $25(48.1)$ & $1.113(0.489-2.537)$ & 0.07 & 0.798 \\
\hline & GG (Arg/Arg) & $4(7.7)$ & $8(15.4)$ & 2.316 (0.601-8.916) & 1.53 & 0.215 \\
\hline & Allele frequency & & & & & \\
\hline & C (Pro) allele & $70(67.3)$ & $63(60.6)$ & $1.340(0.759-2.364)$ & 1.02 & 0.312 \\
\hline & G (Arg) allele & 34 (32.7) & 41 (39.4) & $0.746(0.423-1.317)$ & 1.02 & 0.312 \\
\hline & Dominant model & & & & & \\
\hline & $\mathrm{CC}+\mathrm{CG}$ & $48(92.3)$ & 44 (84.6) & 1 & - & Ref \\
\hline & GG & $4(7.7)$ & $8(15.4)$ & $0.458(0.129-1.629)$ & 1.51 & 0.220 \\
\hline & Recessive model & & & & & \\
\hline & $\mathrm{CC}$ & $22(42.3)$ & $19(36.5)$ & 1 & - & Ref \\
\hline & $\mathrm{GG}+\mathrm{CG}$ & $30(57.7)$ & $33(63.5)$ & $1.274(0.579-2.801)$ & 0.36 & 0.547 \\
\hline \multirow{13}{*}{ Women } & Variant & Control (n, \%) & Obese (n, \%) & OR $(95 \% \mathrm{Cl})$ & $\chi^{2}$ & p \\
\hline & CC (Pro/Pro) & $9(32.1)$ & $9(34.6)$ & 1 & - & Ref \\
\hline & CG (Pro/Arg) & $17(60.7)$ & $15(57.7)$ & $0.882(0.278-2.803)$ & 0.05 & 0.832 \\
\hline & GG (Arg/Arg) & $2(7.1)$ & $2(7.7)$ & 1.000 (0.115-8.730) & 0.00 & 1.000 \\
\hline & Allele frequency & & & & & \\
\hline & C (Pro) allele & $35(62.5)$ & $33(63.5)$ & 0.960 (0.439-2.097) & 0.01 & 0.918 \\
\hline & G (Arg) allele & $21(37.5)$ & $19(36.5)$ & $1.042(0.477-2.278)$ & 0.01 & 0.918 \\
\hline & Dominant model & & & & & \\
\hline & $\mathrm{CC}+\mathrm{CG}$ & $26(92.8)$ & $24(92.3)$ & 1 & - & Ref \\
\hline & GG & $2(7.2)$ & $2(7.7)$ & $0.923(0.120-7.078)$ & 0.01 & 0.939 \\
\hline & Recessive model & & & & & \\
\hline & $\mathrm{CC}$ & $9(32.1)$ & $9(34.6)$ & 1 & - & Ref \\
\hline & $\mathrm{GG}+\mathrm{CG}$ & $19(67.9)$ & $17(65.4)$ & $0.895(0.288-2.776)$ & 0.04 & 0.847 \\
\hline \multirow{12}{*}{ Men } & CC (Pro/Pro) & $13(54.2)$ & $10(38.5)$ & 1 & - & Ref \\
\hline & CG (Pro/Arg) & $9(37.5)$ & $10(38.5)$ & $1.444(0.426-4.897)$ & 0.35 & 0.554 \\
\hline & GG (Arg/Arg) & $2(8.3)$ & $6(23.1)$ & $3.900(0.645-23.598)$ & 2.36 & 0.124 \\
\hline & Allele frequency & & & & & \\
\hline & C (Pro) allele & 35 (72.9) & $30(57.7)$ & $1.974(0.851-4.580)$ & 2.54 & 0.111 \\
\hline & G (Arg) allele & $13(27.1)$ & $22(42.3)$ & $0.506(0.218-1.175$ & 2.54 & 0.111 \\
\hline & Dominant model & & & & & \\
\hline & $\mathrm{CC}+\mathrm{CG}$ & $22(91.6)$ & $20(76.9)$ & 1 & - & Ref \\
\hline & GG & $2(8.4)$ & $6(23.1)$ & $1.891(0.613-5.833)$ & 2.02 & 0.155 \\
\hline & Recessive model & & & & & \\
\hline & $\mathrm{CC}$ & $13(54.1)$ & $10(38.5)$ & 1 & & Ref \\
\hline & $\mathrm{GG}+\mathrm{CG}$ & $11(45.9)$ & $16(61.5)$ & $0.303(0.055-1.677)$ & 1.24 & 0.266 \\
\hline
\end{tabular}


in Table 2. The p53 polymorphism is not linked to obesity risk in either gender (Table 2).

Further, the p53 SNP rs1042522 were separately analyzed in each genotype (CC, CG, and GG) association with age, BMI, glucose, and HOMAIR index (Table 3). Obese participants with p53 (rs1042522) CC, CG, and GG genotypes had higher BMI and HOMA-IR levels than the controls. Glucose levels are significantly different between the obese and control groups with the CC and CG genotypes but without difference in the GG homozygous genotype.

\section{Discussion}

The $p 53$ gene Arg72Pro C $>$ G (rs1042522) polymorphism has been extensively studied as a risk factor in several cancer types (14). The codon 72 polymorphism, which occurs in exon 4 of p53, results in a non-conservative change of an arginine (R72) to a proline (P72) at amino acid 72 and leads to a structural change in the protein that will alter the apoptosis activity (15). Recent studies revealed that this functional change in P53 is associated with insulin resistance, diabetes, and obesity, as well as some cancer types (16).

The waist circumference of participants with the P53 rs1042522 GG genotype expands more over time than those with the CC and CG genotypes, according to a study that involves a large number of people from the Dutch and Finnish populations (17). However, the increased waist circumference has not been associated with obesity. Another study revealed that mice with the R72 variant fed a high-fat diet gained more weight and developed glucose intolerance, insulin resistance, and fatty liver disease compared to the P72 variant (18). The p53 rs1042522 GG genotype significantly increased the risk of obesity in the Saudi population. Additionally, male participants with obesity have a three-fold higher risk in the GG genotype (13). Our study is one of the first to investigate the relationship between the p53 codon 72 polymorphisms and obesity risk. No correlation was found between the p53 rs1042522 variant and obesity risk according to allele and genotype distributions. Additionally, any link between obesity risk and gender was not determined. The relatively small number of obese participants and healthy control groups may limit our study.

A study of 335 patients with type 2 diabetes and 367 healthy controls shows that the p53 codon 72 polymorphism affects insulin resistance independent of body mass in patients with type 2 diabetes. Pro/Pro genotype was associated with lower HOMA-IR values compared to Arg/Arg and Arg/Pro genotypes but without difference in the HOMAIR between diabetic and healthy Pro/Pro genotypes (19). The p53 rs1042522 polymorphism has increased the risk of type 2 diabetes in Chinese Han (20) and Iranian populations (21). Our study revealed that obese participants with p53 (rs1042522) CC, CG, and GG genotypes had higher BMI and HOMA-IR levels than the controls. However, genotype (CC, CG, or GG) is assumed to not affect this condition because people with obesity already have a high BMI and, as a response, high HOMA-IR levels. Glucose levels are significantly different between the obese and control groups with the CC (Pro/Pro) and CG (Arg/Pro) genotypes, whereas no difference in the $\mathrm{GG}(\mathrm{Arg} / \mathrm{Arg})$ homozygous genotype. A relationship may not be determined with glucose because the number of patients with the GG genotype is minimal in both the obese and control groups.

\section{Study Limitations}

The most important limitation of our study is the relatively small number of participants.

\section{Conclusion}

Our study found no relationship between the $p 53$ gene Arg72Pro $C>G$ (rs1042522) polymorphism and the obesity risk. Further research in a large cohort is needed to associate the $p 53$ gene Arg72Pro C $>G$ (rs1042522) variant with obesity risk.

Ethics Committee Approval: The study protocol complies with the 2013 Helsinki Declaration ethical guidelines and was approved by the İstanbul Aydın University Ethics Committee (approval number: B.30.2.A YD.0.00.00.050-06.04/589).

Table 3. Comparisons of variables according to genotype in obese and control groups

\begin{tabular}{|c|c|c|c|c|c|}
\hline Variables & Genotype & $\begin{array}{l}\text { Control }(n=52) \\
\text { median }(25-75 \%)\end{array}$ & Genotype & $\begin{array}{l}\text { Obese }(n=52) \\
\text { median }(25-75 \%)\end{array}$ & p \\
\hline \multirow{3}{*}{ Age (year) } & CC (Pro/Pro) $(n=22)$ & $40.00(32.00-46.00)$ & CC (Pro/Pro) $(n=19)$ & $39.00(29.50-46.00)$ & 0.719 \\
\hline & CG (Pro/Arg) $(n=26)$ & $35.00(33.00-43.00)$ & CG (Pro/Arg) $(n=25)$ & $33.00(29.00-43.00)$ & 0.399 \\
\hline & GG $(\operatorname{Arg} / \operatorname{Arg})(n=4)$ & $32.50(25.00-52.00)$ & GG $(\operatorname{Arg} / \operatorname{Arg})(n=8)$ & $36.00(34.00-42.00)$ & 0.847 \\
\hline \multirow{3}{*}{$\mathrm{BMI}\left(\mathrm{kg} / \mathrm{m}^{2}\right)$} & CC (Pro/Pro) $(n=22)$ & $22.76(21.47-24.22)$ & CC (Pro/Pro) $(n=19)$ & $42.90(40.40-46.20)$ & $0.001^{* * * *}$ \\
\hline & CG (Pro/Arg) $(n=26)$ & $22.53(20.25-24.00)$ & CG (Pro/Arg) $(n=25)$ & $42.00(38.10-45.00)$ & $0.001^{* * * *}$ \\
\hline & GG $(\operatorname{Arg} / \operatorname{Arg})(n=4)$ & $20.93(18.16-23.97)$ & GG $(\operatorname{Arg} / \operatorname{Arg})(n=8)$ & $43.25(36.55-46.35)$ & $0.01^{* * *}$ \\
\hline \multirow{3}{*}{ Glucose (mg/dL) } & CC (Pro/Pro) $(n=22)$ & $78.00(73.00-78.00)$ & CC (Pro/Pro) $(n=19)$ & $107.00(88.50-117.00)$ & $0.001^{* * *}$ \\
\hline & CG (Pro/Arg) $(n=26)$ & $78.00(78.00-85.00)$ & CG (Pro/Arg) $(n=25)$ & $101.00(86.00-128.00)$ & $0.001^{* * * *}$ \\
\hline & $\mathrm{GG}(\operatorname{Arg} / \operatorname{Arg})(n=4)$ & $76.00(70.00-88.50)$ & GG $(\operatorname{Arg} / \operatorname{Arg})(n=8)$ & $100.50(87.00-141.00)$ & 0.249 \\
\hline \multirow{3}{*}{ HOMA-IR index } & CC (Pro/Pro) $(n=22)$ & $1.05(0.62-1.22)$ & CC (Pro/Pro) $(n=19)$ & $18.36(12.45-22.10)$ & $0.001^{* * * *}$ \\
\hline & CG (Pro/Arg) $(n=26)$ & $1.05(0.78-1.05)$ & CG (Pro/Arg) $(n=25)$ & $18.36(11.50-18.36)$ & $0.001^{* * * *}$ \\
\hline & $\mathrm{GG}(\operatorname{Arg} / \operatorname{Arg})(\mathrm{n}=4)$ & $1.03(0.76-1.53)$ & $\mathrm{GG}(\operatorname{Arg} / \operatorname{Arg})(\mathrm{n}=8)$ & $16.60(10.95-24.35)$ & $0.01^{k *}$ \\
\hline
\end{tabular}

Mann-Whitney U; Values are expressed as median (25-75\%). BMI: Body mass index, HOMA-IR Index: homeostatic model assessment for insulin resistance, kg: kilogram, m: meter, mg: miligram, dL: deciliter, $p$-value $p<0.05,{ }^{* * *} p<0.01,{ }^{* * * *} p<0.001$ 
Informed Consent: The informed consent form was obtained from all participants.

Peer-review: Externally peer-reviewed.

Authorship Contributions: Surgical and Medical Practices - B.K., H.A.; Concept - G.K., A.S.; Design - G.K., Z.K.; Data Collection or Processing - G.K., A.S., Z.K.; Analysis or Interpretation - G.K., A.S., Z.K., B.K., H.A.; Literature Search - G.K.; Writing - G.K.

Conflict of Interest: No conflict of interest was declared by the authors.

Financial Disclosure: The authors declared that this study received no financial support.

\section{References}

1. González-Muniesa P, Mártinez-González MA, Hu FB, Després JP, Matsuzawa Y, Loos RJF, et al. Obesity. Nat Rev Dis Primers 2017; 3: 17034.

2. Wright SM, Aronne LJ. Causes of obesity. Abdom Imaging 2012; 37: 730-2.

3. Zwezdaryk K, Sullivan D, Saifudeen Z. The p53/Adipose-Tissue/ Cancer Nexus. Front Endocrinol (Lausanne) 2018; 9: 457.

4. Strycharz J, Drzewoski J, Szemraj J, Sliwinska A. Is p53 Involved in Tissue-Specific Insulin Resistance Formation? Oxid Med Cell Longev 2017; 2017: 9270549.

5. Schwartzenberg-Bar-Yoseph F, Armoni M, Karnieli E. The tumor suppressor p53 down-regulates glucose transporters GLUT1 and GLUT4 gene expression. Cancer Res 2004; 64: 2627-33.

6. Goldstein I, Rotter V. Regulation of lipid metabolism by p53 - fighting two villains with one sword Trends Endocrinol Metab 2012; 23: 56775.

7. Molchadsky A, Ezra O, Amendola PG, Krantz D, Kogan-Sakin I, Buganim $Y$, et al. p53 is required for brown adipogenic differentiation and has a protective role against diet-induced obesity. Cell Death Differ 2013; 20: 774-83.

8. Gloria-Bottini F, Banci M, Saccucci P, Magrini A, Bottini E. Is there a role of p53 codon 72 polymorphism in the susceptibility to type 2 diabetes in overweight subjects? A study in patients with cardiovascular diseases. Diabetes Res Clin Pract 2011; 91: e64-e67.

9. Chen RH, Chang CT, Wang TY, Huang WL, Tsai CH, Tsai FJ. p53 codon 72 proline/arginine polymorphism and autoimmune thyroid diseases. J Clin Lab Anal 2008; 22: 321-6.
10. Pim D, Banks L. p53 polymorphic variants at codon 72 exert different effects on cell cycle progression. Int J Cancer 2004; 108: 196-9.

11. Burgdorf KS, Grarup N, Justesen JM, Harder MN, Witte DR, Jorgensen T, et al. Studies of the association of Arg72Pro of tumor suppressor protein p53 with type 2 diabetes in a combined analysis of 55,521 Europeans. PLoS One 2011; 6: e15813.

12. Marin MC, Jost CA, Brooks LA, Irwin MS, O'Nions J, Tidy JA, et al. A common polymorphism acts as an intragenic modifier of mutant p53 behaviour. Nat Genet 2000; 25: 47-54.

13. Sabir JSM, El Omri A, Shaik NA, Banaganapalli B, Hajrah NH, Zrelli H, et al. The genetic association study of TP53 polymorphisms in Saudi obese patients. Saudi J Biol Sci 2019; 26: 1338-43.

14. Kodal JB, Vedel-Krogh S, Kobylecki CJ, Nordestgaard BG, Bojesen SE. TP53 Arg72Pro, mortality after cancer, and all-cause mortality in 105,200 individuals. Sci Rep 2017; 7: 336.

15. Sakamuro D, Sabbatini P, White E, Prendergast GC. The polyproline region of $\mathrm{p} 53$ is required to activate apoptosis but not growth arrest. Oncogene 1997; 15: 887-98.

16. Kung CP, Murphy ME. The role of the p53 tumor suppressor in metabolism and diabetes. J Endocrinol 2016; 231: R61-R75.

17. Reiling E, Lyssenko V, Boer JM, Imholz S, Verschuren WM, Isomaa B, et al. Codon 72 polymorphism (rs1042522) of TP53 is associated with changes in diastolic blood pressure over time. Eur J Hum Genet 2012; 20: 696-700.

18. Kung CP, Leu JI, Basu S, Khaku S, Anokye-Danso F, Liu Q, et al. The P72R Polymorphism of p53 Predisposes to Obesity and Metabolic Dysfunction. Cell Rep 2016; 14: 2413-25.

19. Bonfigli AR, Sirolla C, Testa R, Cucchi M, Spazzafumo L, Salvioli S, et al. The p53 codon 72 (Arg72Pro) polymorphism is associated with the degree of insulin resistance in type 2 diabetic subjects: a crosssectional study. Acta Diabetol 2013; 50: 429-36.

20. Qu L, He B, Pan Y, Xu Y, Zhu C, Tang Z, et al. Association between polymorphisms in RAPGEF1, TP53, NRF1 and type 2 diabetes in Chinese Han population Diabetes. Res Clin Pract 2011; 91: 171-6.

21. Haghnazari L, Sabzi R. Relationship between TP53 and interleukin-6 gene variants and the risk of types 1 and 2 diabetes mellitus development in the Kermanshah province. J Med Life 2021; 14: $37-$ 44. 